\title{
Respuesta inmune en la neuromielitis óptica
}

\author{
I. LOPATEGUI CABEZAS, M. CERVANTES LLANO ${ }^{1}$, G. PENTÓN ROL ${ }^{1}$ \\ Departamento de Bioquímica. Instituto de Ciencias Básicas y Preclínicas "Victoria de \\ Girón". 'Centro de Ingeniería Genética y Biotecnología. Ciudad de La Habana. Cuba
}

\author{
IMMUNE RESPONSE IN OPTIC NEUROMYELITIS
}

\begin{abstract}
RESUMEN
La neuromielitis óptica es una enfermedad inflamatoria, desmielinizante y autoinmune del sistema nervioso central. En el presente trabajo se realiza una revisión de los diferentes mecanismos involucrados en la patogénesis de la neuromielitis óptica, se analiza el papel de los eosinófilos, de los anticuerpos contra antígenos propios y de las células $\mathrm{T}$ reguladoras en la enfermedad. En la neuromielitis óptica existe un predominio de la respuesta inmune humoral, la enfermedad se caracteriza por el depósito de inmunocomplejos, activación del complemento, producción de anticuerpos contra proteínas de la mielina y reclutamiento de eosinófilos en las lesiones. Existe además un aumento de la expresión de receptores de quimiocinas como el CCR3, específico de células TH2, la enfermedad está asociada predominantemente a una respuesta TH2.
\end{abstract}

PALABRAS CLAVES: Neuromielitis óptica. Devic. Autoinmunidad. Respuesta inmune.

\begin{abstract}
The Optic Neuromyelitis is an inflammatory and autoimmune illness of the central nervous system. Presently work is carried out a revision of the different mechanisms involved in the pathogenesis of the Optic Neuromyelitis, the paper of the eosinophils is analyzed, of the antibodies against own antigens and of the regulatory $T$ cells in the illness. In the Optic Neuromyelitis is very important the humoral response, the illness exists it is characterized by the immunocomplex deposit, activation of the complement, production of antibodies against proteins of the myelin and eosinophils recruitment in the lesions. It also exists an increase of the expression of chemokines receptors like the CCR3, specific of TH2 cells; the illness is associate predominantly to a TH2 response.
\end{abstract}

KEY WORDS: Optic neuromyelitis. Devic. Autoimmunity.

Lopategui Cabezas I, Cervantes Llano M, Pentón Rol G. Respuesta inmune en la neuromielitis óptica. An Med Interna (Madrid) 2008; 25: 362-365.

\section{INTRODUCCIÓN}

La neuromielitis óptica (NMO) es considerada una enfermedad desmielinizante del sistema nervioso central (SNC), de naturaleza autoinmune. Diferentes mecanismos están involucrados en la patogénesis de esta agresiva enfermedad. La pronunciada reactividad de las inmunoglobulinas y la activación del complemento en los lugares de lesión vascular sugieren que el espacio peri-vascular puede ser el sitio primario del daño en la NMO (1). Esto pudiera deberse a anticuerpos contra antígenos vasculares o antígenos liberados dentro del SNC, durante el proceso destructivo, que pueden llegar al espacio peri-vascular y ser reconocidos por anticuerpos provenientes de la circulación. Finalmente, puede estar involucrada una reacción inflamatoria no específica, iniciada por la deposición de complejos inmunes circulantes.

En este escenario, la vía clásica del complemento se activa, permitiendo el reclutamiento de macrófagos activados hacia los sitios peri-vasculares. Los macrófagos activados, conjuntamente con los eosinófilos y los neutrófilos, localmente generan citocinas, proteasas y radicales libres del oxígeno/nitrógeno que pueden contribuir al daño vascular y parenquimatoso. Lo anterior provoca una destrucción no selectiva de la materia blanca y gris, incluyendo axones y oligodendrocitos (2). Una localización similar fue encontrada en casos severos de glicoproteína mielínica del oligodendrocito (MOG)-encefalitis autoinmune experimental (EAE) (3); este fenómeno es probablemente debido a la isquemia inducida por el edema.

Posteriormente nuevos antígenos liberados durante el proceso destructivo pueden amplificar la respuesta inmune destructiva en la enfermedad (2).

Dentro del SNC inflamado, los linfocitos, astrocitos, macrófagos y microglias representan las principales fuentes de producción de citocinas. Atendiendo al perfil de citocinas que son segregadas por las células T CD4+ estas se dividen en células TH1, que producen grandes cantidades de IFN- $\gamma$ y TNF- $\alpha$, y células TH2, que producen en mayor medida IL-4, IL-10 e IL-13 (4). En la NMO existe un desequilibrio TH1/TH2, predominando una respuesta celular TH2, como se ha demostrado en un gran número de estudios $(5,6)$.

Trabajo aceptado: 12 de marzo de 2008 


\section{PAPEL DE LOS EOSINÓFILOS}

Una de las características más novedosas que se describen en la histopatología de las lesiones activas de la NMO es la intensidad de la infiltración meníngea y perivascular de la médula espinal con eosinófilos y neutrófilos. Los eosinófilos son funcionalmente activos y probablemente contribuyan al proceso inflamatorio destructivo (7), liberan gránulos básicos con proteínas tales como la neurotoxina, la proteína catiónica y la peroxidasa (8). Estos gránulos tienen propiedades citotóxicas y sirven como marcadores de activación de estas células (9). Además, los eosinófilos son una fuente importante de IL-4, la cual puede causar un cambio en el perfil de citocinas de TH1 a TH2 (5).

Existen evidencias de la expresión de CCR3 en las lesiones de la NMO. CCR3 es el principal receptor para la quimiocina Eotaxina, un potente quimio-atrayente de eosinófilos que es selectivamente expresado en células TH2 (10). Por lo tanto, la señalización de la eotaxina a través del CCR3 es un importante índice de reclutamiento de eosinófilos (11).

Los gránulos de eosinófilos de la proteína básica de la mielina (MBP) son fuertemente tóxicos para las células endoteliales de forma dosis-dependiente y pueden contribuir al daño vascular en la vasculitis necrotizante asociada con infiltración de eosinófilos $(12,13)$. Existe un reporte de eosinofilia en el líquido cefalorraquídeo en un niño con mielitis transversa recurrente (14) y otro de vasculitis eosinofílica y pericarditis en un paciente que presentaba una enfermedad tipo NMO (15).

Por otra parte, la activación del complemento genera diferentes péptidos activos biológicamente que tienen potencialidades quimioatrayentes. El más relevante clínicamente es el factor quimiotáctico $\mathrm{C} 5 \mathrm{a}$, un producto de ruptura del quinto componente de este complejo. Además de su actividad quimiotáctica, C5a es un potente factor para la activación de eosinófilos (9). La activación del complemento dentro de las lesiones puede inducir por tanto la producción de factores quimiotácticos, resultando en la activación secundaria de eosinófilos y la consiguiente liberación de proteínas de sus gránulos en las paredes de los vasos (9).

El infiltrado eosinofílico observado en los casos de NMO ha sido asociado con el tratamiento crónico con Interferón- $\beta$. En EAE por transferencia pasiva, los eosinófilos invaden el nervio óptico y la médula espinal de 7 a 8 días después de transferidas las células T.

\section{PAPEL DE LOS ANTICUERPOS ANTI-MOG, ANTI-MBP Y ANTI-PROTEÍNA UNIDORA DE CALCIO DE LA ASTROGLIA (S1OOß)}

En la NMO puede encontrarse una prominente respuesta de anticuerpos contra antígenos endógenos de la mielina, tales como MOG. Un reciente estudio analizó la respuesta de anticuerpos contra MOG, MBP y S100 $\beta$ en el suero de 4 casos de Enfermedad de Devic (17). Los autores reportaron una pronunciada respuesta antiMOG, específicamente al epítope 63-87, en todos los pacientes, anticuerpos antiMBP en dos pacientes $\mathrm{y}$ anticuerpos antiS100 $\beta$ en un paciente.

\section{PAPEL DE LAS CÉLULAS T REGULADORAS}

Existen múltiples mecanismos endógenos que inhiben el desarrollo tímico de las células T autorreactivas funcionales.
A pesar de esto, persisten poblaciones de células T CD4+ autorreactivas en individuos normales que retienen la capacidad de iniciar una enfermedad autoinmune. Es por eso que son necesarios mecanismos de regulación adicionales que operan en la periferia para proteger contra la generación de respuestas inmunes dirigidas a lo propio (18).

Se ha dedicado una considerable atención a las células $\mathrm{T}$ CD4+ que expresan la cadena $\alpha$ del receptor de IL-2 (CD25) ya que la depleción de estas células en ratones sanos induce un Síndrome poliautoinmune (19). Esta observación avala la importancia del mantenimiento de los niveles y la funcionalidad adecuada de esta subpoblación celular para evitar la generación de una enfermedad autoinmune (EA).

Las células con propiedades reguladoras pueden dividirse en 2 tipos: las naturales, generadas por el timo y las inducidas, generadas por estimulación antigénica bajo condiciones especiales en la periferia, las inducidas también han sido denominadas TH3 ó células reguladoras adaptativas (20).

Los mecanismos de supresión para las células T reguladoras inducidas son fundamentalmente a través de la secreción de citocinas, como la IL-10 y el Factor de Crecimiento Transformante $\beta$ (TGF- $\beta$ ) y para las naturales se plantea el contacto célula-célula (21). Sakaguchi y cols. fueron los primeros en identificar a la molécula CD25 como marcador de células T reguladoras (22) y $\mathrm{CD} 45 \mathrm{RB}$ ha sido identificado posteriormente como otro marcador de estas células (23).

En ratones, del 5-10\% de las células CD4+ y el 1\% de las células CD8+ expresan el CD25 high y CD45RB ${ }^{\text {low }}(24)$. En humanos las células T reguladoras son del 6-10\% de las células CD4+ (25). Las células $\mathrm{T}$ reguladoras muestran elevados niveles de CD11a (LFA-1), CD44, CD54 (ICAM-1) y CD103 en ausencia de aparente estimulación antigénica (26). Adicionalmente producen CD152 (CTLA-4), una molécula solamente expresada después de la activación celular (27).

Las células T reguladoras expresan elevados niveles de los de receptores de quimiocinas CCR5 y su contraparte en el humano CCR4 y CCR8 (28). Este patrón distintivo de expresión de receptores de quimiocinas sugiere que pueden ser rápidamente reclutadas a los sitios de inflamación, y por tanto, ejercer eficientemente el control de la respuesta inmune. Muchos autores han reportado la expresión del factor de necrosis tumoral inducido por glucocorticoides (GITR) en las células CD4+CD25+ (29).

Recientes estudios han mostrado que las células $\mathrm{T}$ reguladoras están enriquecidas en CD25 $5^{\text {high }}$. Las células T CD4+CD25 $5^{\text {high }}$ inhiben completamente la proliferación y secreción de citocinas por las células T CD4+. Las células T CD4+CD25 $5^{\text {high }}$ difieren de las células T CD4+CD25+ en los niveles de expresión de CD45RO y HLA-DR (30).

Se han descrito células $T$ reguladoras derivadas del timo en ratones y humanos. En ratones, la ausencia de ellas provoca autoinmunidad órgano-específica (24).

Recientemente, se ha demostrado que el factor transcripcional Foxp3 es importante para la función de las células $\mathrm{T}$ reguladoras en ratones. Foxp3 parece ser un marcador algo exclusivo de las células $\mathrm{T}$ reguladoras (31). Aun así no se excluye la posibilidad de expresión del mismo en otras condiciones de activación y en otras poblaciones celulares (32). La expresión de Foxp3 es típica de células CD4+CD25+ y se correlaciona con la actividad supresora de estas células (33). Estos datos sugieren que el fallo en la generación de las células $\mathrm{T}$ reguladoras pudiera contribuir a las EA y que Foxp3 podría tener un papel terapéutico en tales enfermedades. 
El mecanismo de acción de las células T reguladoras inducidas involucra al TGF- $\beta$ (34). Las células asesinas naturales (NK), que tienen además propiedades de células $\mathrm{T}$ pueden contribuir a esta inmunoregulación (35). La IL-10, citocina $\mathrm{TH} 2$, producida por células T reguladoras inducidas, monocitos y macrófagos, enlentece la progresión de las EA en modelos experimentales (36). La IL-10 puede también jugar un papel en estas enfermedades por disminución de la sobrevida de los eosinófilos activados (37). Estos datos sugieren que la IL-10 y el TGF- $\beta$ producidos por las células T reguladoras pueden inhibir las respuestas TH1 y TH2, siendo los mediadores de esta regulación.

\section{POSIBLES EXPLICACIONES PARA LA TOPOGRAFÍA RESTRINGIDA DE LAS LESIONES NMO}

Se desconocen las razones por las cuales la médula espinal y el nervio óptico son afectados con preferencia en la NMO. Es posible que estos sitios tengan un antígeno vascular o del SNC restringido, o que tengan una vulnerabilidad particular al daño mediado por anticuerpos debido a la inherente debilidad de la Barrera Hematoencéfalica (BHE). La BHE es altamente impermeable a proteínas plasmáticas y leucocitos circulantes y puede proteger al SNC de una reacción inmunológica. Sin embargo, en algunas áreas donde no es efectiva, tales como las raíces de los nervios espinales, puede suceder que anticuerpos patogénicos circulantes accedan al SNC y difundan a la vecindad inmediata (13).

En los modelos de EAE las lesiones activas afectan predominantemente la médula espinal y el nervio óptico retrobulbar. Las lesiones en estos dos sitios son reflejo del alto grado de permeabilidad de la BHE en estas regiones comparado con el cerebro (38).

La permeabilidad de la BHE incrementada en la médula espinal puede ser debido a propiedades vasculares inherentes a esta región donde los capilares son más largos que en el cerebro. Por tanto, con un proceso inflamatorio de fondo y en presencia de títulos extremadamente elevados de anticuerpos, las lesiones pueden preferentemente, pero no exclusivamente, afectar la médula espinal y el nervio óptico. Esta hipótesis es compatible con la observación de que en estadios tardíos de la $\mathrm{NMO}$, las lesiones a menudo se diseminan a otras regiones del SNC (1).

En resumen, como se ha señalado, existen diferentes mecanismos involucrados en la patogénesis de la NMO. Estrategias terapéuticas futuras diseñadas para limitar el efecto perjudicial de la activación del complemento, la degranulación de eosinófilos y neutrófilos, activación de macrófagos y de la microglia deben ser investigadas.

\section{Bibliografía}

1. Wingerchuk DM .Neuromyelitis optica. Adv Neurol 2006; 98: 319-33.

2. Cree BA, Goodin DS, Hauser SL. Neuromyelitis Optica. Semin Neurol 2002; 22 (2): 105-22.

3. Storch MK, Stefferl A, Brehm U, Weissert R, Wallstrom E, Kerschensteiner M, et al. Autoimmunity to myelin oligodendrocyte glycoprotein in rats mimics the spectrum of multiple sclerosis pathology. Brain Pathol 1998; 8: 681-94.

4. Sprent J, Surh C. Cytokines and T cell homeostasis. Immunology letters 2003; 85: 145-9.

5. Narikawa K, Misu T, Fujihara K, Nakashima I, Sato S, Itoyama Y. CSF chemokine levels in Relapsing Neuromyelitis Optica and Multiple Sclerosis. J Neuroinmunol 2004; 149 (1-2): 182.

6. Kohm AP, Carpentier PA, Miller SD. Regulation of experimental autoinmune encephalomyelitis (EAE) by $\mathrm{CD} 4+\mathrm{CD} 25+$ regulatory $\mathrm{T}$ cell. Novartis Found Symp. 2003; 252: 45-52; discussion 52-4, 106-14.

7. Sallusto F, Lenig D, Mackay CR, Lanzavecchia A. Flexible programs of chemokines receptors expression on human polarized T helper 1 and 2 lymphocytes. J Exp Med 1998; 187: 875-83.

8. de Sese J. Neuromyelitis Optica. Arch Neurol 2003; 60 (9): 1336-8.

9. Venge P. Monitoring of asthma inflammation by serum measurements of eosinophil cationic protein (ECP): a new clinical approach to asthma management. Resp Med 1995; 89: 1-2.

10. Ponath PD, Qin S, Post TW, Wang J, Wu L, Gerard NP, et al. Molecular cloning and characterization of human eotaxin receptor expressed selectively on eosinophils. J Exp. Med 1996; 183: 2437-48.

11. Wingerchuk DM. Neuromyelitis Optica: Current concepts . Front Biosci 2004; 9: 834-40.

12. Correale J, Fiol M. Activation of humoral immunity and eosinophils in Neuromyelitis Optica. Neurol 2004; 63: 2363-70.

13. Lucchinetti CF, Mandler RN, McGavern D, Bruck W, Gleich G, Ransohoff RM, Trebst C, Weinshenker B, Wingerchuk D, Parisi JE, Lassman H. A role for humoral mechanism in the pathogenesis of Devic's neuromyelitis optica. Brain 2002; 125: 1450-61.

14. Snead OC $3^{\text {er }}$, Kalavsky SM. Cerebrospinal fluid eosinophilia: a manifestation of a disorder resembling multiple sclerosis in childhood. J Pediatr 1976; 89: 83-4.
15. Tanphaichitr K. Multiple sclerosis associated with eosinophilic vasculitis, pericarditis, and hipocomplementemia. Arch Neurol 1980; 37: 314415.

16. Jiang H. et al. Regulatory CD8+ T cell fine - tube the myelin basic protein reactive $\mathrm{T}$ cell receptor during experimental autoimmune encephalomyelitis. PNAS 2003; 14: 8379-83.

17. Haase CG, Schmidt S. Detection of brain-specific autoantibodies to myelin oligodendrocyte glycoprotein, S100beta and myelin basic protein in patients with Devic's neuromyelitis optica. Neurosci Lett 2001; 307: 131-3.

18. Jacobi C, Stingele K, Kretz R, Hartmann M, Storch-Hagenlocher B, Breitbart A, Wildemann B. Neuromyelitis optica (Devic's syndrome) as first manifestation of systemic lupus erythematosus. Lupus 2006; 15 (2): 107-9.

19. Assano M, el al. Autoimmune disease as a consequence of developmental abnormality of a T cell subpopulation. J Exp Med 1996; 184: 387-96.

20. Bluestone JA, et al. Natural versus adaptive regulatory T cells. Nat Rev Immunol 2003; 3: 253-7

21. Groux H. Type 1 T-regulatory cells: their role in the control of immune responses. Transplantation 2003; 75: 8S-12S.

22. Sakaguchi S, et al. Organ-specific autoimmune diseases induced in mice by elimination of T cell subset: I. Evidence for the active participation of $\mathrm{T}$ cells in natural self-tolerance; déficit of a $\mathrm{T}$ cell subset as a posible cause of autoimmune disease J Exp Med 1985; 161: 72-87

23. Powrie F, et al. Phenotypically distinct subsets of CD4+ T cells induce or Project from chronic intestinal inflammation in C. B-17 scid mice. Int Immunol 1993; 5: 1461-71.

24. Itoh M, et al. Thymus and autoimmunity: production of CD25+CD4+ naturally anergic and suppressive T cells as a key function of the thymus in maintaining immunologic self-tolerance J Immunol 1999; 162: 5317-26.

25. Ng WF, el at. Human CD4+CD25+ cells: a naturally ocurring population of regulatory T Blood cells 2001; 98: 2736-44.

26. McHugh RS, et al. CD4+CD25+ immunoregulatory $\mathrm{T}$ cells: gene expression analysis reveals a functional role for the glucocorticoidinduced TNF receptor. Immunity 2002; 16: 311-23. 
27. Takahashi $\mathrm{T}$, et al. Immunologic self-tolerance maintained by CD25+CD4+ regulatory $\mathrm{T}$ cells constitutively expressing cytotoxic $\mathrm{T}$ lymphocyte-associated antigen-4. J Exp Med 2000; 192: 303-10.

28. Bystry RS, et al. B cells and professional APCs recruit regulatory T cells via CCL4. Nat Immunol 2001; 2: 1126-32.

29. McHugh RS, et al. CD4+CD25+ immunoregulatory $\mathrm{T}$ cells: gene expression analysis reveals a functional role for the glucocorticoidinduced TNF receptor 2002; Immunity 16: 311-23.

30. Baecher-Allan $\mathrm{C}$, et al. CD4+CD25high regulatory cells in human peripheral blood. J Immunol 2001; 167: 1245-53.

31. Brunkow ME, et al. Disruption of a new forkhead/winged-helix protein, scurfin, results in the fatal lymphoproliferative disorder of the scurfy mouse. Nat Genet 2001; 27: 68-73.

32. Morgan ME, et al. Expression of FOXP3 mRNA is not confined to CD4+CD25+ T regulatory cells in humans. Hum Immunol 2005; 1: 13-20.
33. Walker MR, et al. Induction of Foxp3 and acquisition of $\mathrm{T}$ regulatory activity by stimulated human CD4+CD25- T cells. J Clin Invest 2003; 112: $1437-43$

34. Nakamura $\mathrm{K}$, et al. Cell contact-dependent immuno-suppression by CD4+CD25+ regulatory T cells is mediated by cell surface-bound transforming growth factor beta. J Exp Med 2001; 194: 629-44.

35. Bendelac A, et al. Mouse CD1-specific NK1 T cells: development, specificity, and function. Annu Rev Imunol 1997; 15: 535-62.

36. Moore KW, et al. Interleukin-10 and the interleukin-10 receptor. Annu Rev Immunol 2001; 19: 683-765.

37. Takanashi S, et al. Interleukin-10 inhibits lipopolysaccharide-induced survival and cytokine production by human peripheral blood eosinophils. J Exp Med 1994; 180: 711-5.

38. Sakaguchi S. Regulatory T cell: mediating compromises between host and parasite. Nature Immunol 2003; 1: 1-4. 